\title{
AUTORIDADE PRIVADA NA GOVERNANÇA DA INTERNET \\ Regimes de nomes e domínios na América Latina
}

\section{Pablo Holmes}

https://orcid.org/0000-0003-3612-3283

\section{Kimberly Anastácio}

https://orcid.org/0000-0003-4298-2543

(1) Universidade de Brasília (UnB), Brasília - DF, Brasil. E-mail: pabloholmes@unb.br

(2) Universidade de Brasília (UnB), Brasília - DF, Brasil. E-mail: anastaciokimberly@gmail.com

DOI: $10.1590 / 3510218 / 2020$

\section{Introdução}

O arranjo regulatório da internet costuma ser descrito pela literatura como um esquema de governança policêntrica (Scholte, 2004; J. A. Scholte, 2017) baseada em uma coordenação entre o setor público (representado por Estados e organizaçóes internacionais), empresas e a sociedade civil, no que se convencionou chamar multissetorialismo ${ }^{1}$ (Weiser $\&$ Waz, 2012). A governança da internet (GI) é vista, assim, como um dos casos de emergência de novas formas regulatórias transnacionais em que há uma profunda transformação do exercício de autoridade (Bislev \& Flyverbom, 2008; Cutler, 2009; Hall \& Biersteker, 2002a).

$\mathrm{Na}$ literatura sobre governança transnacional e governança global, observa-se, há algum tempo, a emergência de novas formas de regulação, para as

Artigo recebido em: 17/01/2019

Aprovado em: 17/10/2019 quais a noção estritamente hierárquica de autoridade pública centralizada e fundada no "monopólio estatal da força" torna-se ferramenta explicativa pouco produtiva (Hall \& Biersteker, 2002b). Em lugar de uma autoridade hierárquica e centralizada, definida juridicamente como o fundamento soberano de legitimação de qualquer regulação ou contrato (Troper, 2016), observa-se uma desagregação da autoridade (Porter, 2008), a emergência de formas de autoridade privada e mecanismos indiretos de regulação. Atores privados participam cada vez mais da formulação e da implementação de mecanismos regulatórios não coercitivos (Black, 2001), que são muitas vezes baseados na coordenação de expectativas por meio da fixação de contratos (Cutler, 2002), standards (Higgins \& Hallstrom, 2007), formulação de rankings (Espeland \& Sauder, 2007), estruturação de dados, indicadores ou realização de auditorias (Davis, Fischer, Kinsbury, \& Merry, 2012; Hansen \& Porter, 2017). 
A literatura sobre governança certamente não se limita à observação de fenômenos explicitamente transnacionais, como a internet. Originado na economia neo-institucional e recebida na ciência política sobretudo por meio da literatura sobre New Public Management, o debate sobre governança se tornou um dos mais relevantes da década no interior da disciplina, com dimensão interdisciplinar (Kersbergen \& Waarden, 2004; Zumbansen, 2012). Essa literatura descreve a "transição do governo para a governança” (Rhodes, 2012; Kjaer, 2016) como uma passagem da regulação por meio de hierarquias para uma regulação por meio de redes, em que há uma valorização de mecanismos contratuais, arranjos cognitivos e acordos horizontais de coordenação, assim como de mecanismos de autorregulação que alteram a relação entre reguladores e atores regulados (Rhodes, 1996; Stoker, 1998; Zumbansen, 2012).

Pode-se dizer que a GI é um caso paradigmático na transição para a semântica da "governança". Por suas características de surgimento, operação e funcionamento, a internet é um espaço em que a regulação, desde o princípio, se deu com forte presença de atores não-estatais, tanto para a formulaçáo dos protocolos que se deram no contexto militar-universitário, como para a gestão de seus recursos que foi delegada à gestão de uma comunidade de engenheiros, técnicos e empresas (Kleinwächter, 2007). Hoje, depois de diversas transformaçóes, pode-se dizer que a semântica do multissetorialismo domina a gramática legitimatória da GI, sendo proclamada por atores tão insuspeitos como o governo dos EUA, a União Internacional das Telecomunicações (UIT), a Corporação da Internet para Atribuição de Nomes e Números (ICANN) e a maioria dos Estados (Doria, 2013). E isso parece ter consequências práticas, mesmo no contexto em que Estados nacionais tentam impor formas de autoridade hierárquicas. Há uma tendência ao estabelecimento de alguma forma de multissetorialismo, nem que seja como retórica legitimatória - tendência que tem também contradiçôes e provoca diversos tipos de conflito.

$\mathrm{O}$ presente artigo se engaja no debate acerca da emergência da autoridade privada, no caso da GI, a partir de um estudo comparativo entre os distintos regimes de regulação de domínios de topo de código de país, ccTLDs, ${ }^{2}$ em quatro países da América
Latina: Argentina, Brasil, Colômbia e México. Com a atenção voltada para o desenvolvimento desses quatro regimes, tentamos observar suas distintas trajetórias, desde o início da internet nesses países, apontando a progressiva afirmação de uma semântica regulatória baseada no multissetorialismo nesses diferentes contextos. Propomos, assim, que a GI, no caso dos ccTLDs, exibe características que evidenciam a emergência de novas formas de exercício de autoridade em que são alterados os papeis do Estado e da sociedade em processos políticos de regulação social. Com isso, mesmo que o multissetorialismo apresente especificidades a depender do país, ou que seja mais ou menos capturado por atores e interesses estatais ou privados, ele parece servir como regra de autoridade para a regulação do setor.

Realizamos uma pesquisa com levantamento documental, participação em encontros internacionais de GI e entrevistas semiestruturadas, escolhidas a partir do método de snowball. ${ }^{3}$ Foram conduzidas 21 entrevistas semiestruturadas com 17 indivíduos que trabalham ou trabalharam com ccTLDs, provenientes de órgão estatais, universidades, do setor privado e de Organizaçóes Não-Governamentais, em todos os países pesquisados. Faremos então uma exposição esquemática dos nossos achados de campo, apontando para a expectativa compartilhada de que a regulação dos ccTLDs é legítima se atender à regra multissetorial.

$\mathrm{Na}$ seção 2, a seguir, faremos uma breve revisão do debate sobre GI, relacionando-o com a existência de autoridade privada em novos esquemas regulatórios pós-nacionais. Logo após, na seção 3, apresentaremos os quatro casos investigados, explicando suas diferentes trajetórias e apontando a convergência para o modelo multissetorial. Na seção seguinte 4 , discutiremos a convergência desses regimes para um esquema de multissetorialismo que, embora com especificidades, opera como uma regra de autoridade para a governança desse setor.

\section{A governança da internet e a emergência da autoridade privada}

A popularização da internet, nos anos 1990, trouxe consigo a impressão de que a rede seria um 
inédito terreno de inovação e experimentalismo sociais. A geração de técnicos e engenheiros responsáveis por desenvolvê-la nas universidades norte-americanas pouco tinha a ver com os interesses do departamento de defesa dos EUA que, por meio da ARPA (Advanced Research Projects Agency), financiava seus esforços (Kleinwächter, 2007). Tendo crescido sob a influência do movimento pacifista de 1968, essa geração, em que um dos ícones foi Jon Postel, via a internet como um espaço potencial para a afirmação de uma forma de convivência sem hierarquias ou mediação de autoridades centralizadas. A internet seria, para eles, um espaço de autorregulação em que o Estado não seria bem-vindo, e onde a sociedade poderia experimentar novas formas de coordenação social (Barlow, 1996). A história posterior demonstrou que esse impulso visionário inicial teria desafios importantes, e claros limites. A internet cresceu rapidamente, passando a interferir em sensíveis interesses econômicos, políticos e geopolíticos (Drezner, 2004), e isso gerou uma série de transformaçóes importantes na GI.

A internet é uma estrutura complexa, cuja regulação envolve os chamados (i) recursos críticos da rede - conhecido como "governança da internet", num sentido estrito -, e diz respeito à operação dos endereços e nomes de domínio que possibilitam a coordenação das conexóes da rede e sua interoperabilidade; (ii) a infraestrutura física da rede, baseada em cabos, serviços telefônicos e na rede de servidores que proveem acesso; (iii) a regulação da segurança na circulação de dados, sejam eles sensíveis ou não, assim como da privacidade dos usuários; e (iv) a dimensão do direito cibernético, que envolve a regulação de áreas como a proteção da propriedade intelectual e a definição de distintas formas de crimes cibernéticos (van Eeten \& Mueller, 2013). Todas essas dimensóes são partes essenciais do processo por meio do qual a rede mundial é regulada e cada uma tem peculiaridades que dificilmente se deixam compreender de acordo com a mesma abordagem teórica. Enquanto alguns temas são mais sensíveis à autoridade estatal, como o direito cibernético (van Eeten \& Mueller, 2013), outros são quase exclusivamente objeto de decisóes comerciais privadas de empresas, provedores de serviço, servidores de registro ou mesmo prestadores de serviço online responsáveis por grande parte da infraestrutura física da rede (van Eeten \& Mueller, 2013).

Considerando os recursos críticos, as transformaçôes da GI levaram à acumulação de uma série de prerrogativas pela Corporação da Internet para a Atribuição de Nomes e Números $\left(\mathrm{ICANN}^{4}\right)$. A ICANN foi constituída por iniciativa do governo de Bill Clinton, em 1998, como uma empresa privada segundo a legislação do Estado da Califórnia (Zittrain, 1999). Ela consistia numa tentativa de privatizar a gestão da internet depois que diversos Estados passaram a pressionar o governo dos EUA para desvincular a gestão da internet da ARPA (Kleinwächter, 2007). Na prática, a gestão dos recursos críticos havia ficado durante longo tempo nas mãos de uma pessoa: Jon Postel, que desenvolveu grande parte da infraestrutura inicial da rede e de sua gestáo com o apoio de uma comunidade de técnicos e engenheiros organizados na Internet Engineering Task Force (IETF), por meio de um modelo de consulta baseado nos Requests for Comments (RFC).

A atribuição de nomes e domínios ficava a cargo da Autoridade para Atribuição de Números da Internet (IANA ${ }^{5}$ ), criada por Postel em 1988, por meio de delegação da Administração Nacional de Telecomunicaçóes e Informação (NTIA), órgão de governo dos Estados Unidos. ${ }^{6}$ Inicialmente, a IANA era submetida ao Information Science Institute, dirigido por Postel na Universidade do Sul da Califórnia, tendo passado, com a criação da ICANN em 1998, a ser uma autoridade subordinada diretamente à NTIA. Em 2013, sob forte pressão da comunidade internacional, iniciou-se um processo de privatização da IANA, que se encerrou em 2016, quando ela passou a ser um departamento da ICANN.

A pressão política de Estados nacionais, sobretudo de países do Sul global, evidenciada no processo de transição das funçóes da IANA, havia se intensificado desde o começo da década de 1990. Em 2003, por convocação do Secretário Geral da ONU, ocorreu a Cúpula Mundial sobre a Sociedade da Informação - World Summit on The Information Society (WSIS), realizada em duas rodadas: a primeira em Genebra (2003), e a segunda em Túnis (2005), que originou uma 
importante declaração multilateral (Kleinwächter, 2007) - a Agenda de Túnis -, fonte da definição mais conhecida do que se convencionou chamar de "governança da internet" e multissetorialismo. Segundo esta definição:

[...] a governança da internet é o desenvolvimento e aplicação por governos, pelo setor privado e pela sociedade civil, em seus respectivos papeis, de princípios, normas, regras, procedimentos decisórios e programas compartilhados, que determinam a evolução e o uso da Internet. (ITU/UN, 2005). ${ }^{7}$

Ao menos no primeiro momento, as resoluções do WSIS consistiram, em grande medida, em declarações de intenção sem consequências imediatas. Os atores mais relevantes na governança prática dos recursos críticos da internet, como a ICANN e a IANA, por exemplo, não tiveram participação relevante nas formulaçóes da Cúpula (Raymond \& Denardis, 2015). Mas o WSIS teve efeitos de longo prazo. Um deles foi a criação do Fórum de Governança da Internet (IGF), uma entidade sem poder regulatório, mas com estrutura deliberativa e influência, que se demonstrou importante polo multissetorial de discussão. E, embora os recursos críticos da internet tenham continuado a ser geridos por um arranjo jurídico privado, organizado ao redor do ICANN e suas subsidiárias, sob relação contratual com a NTIA, o WSIS foi fundamental no gradativo processo de desvinculação da GI do governo dos EUA com a desvinculação da IANA de seus laços governamentais em 2016 (Hofmann, Katzenbach, \& Gollatz, 2017; Kleinwächter, 2007).

Esse processo de transformação na GI recebeu grande impulso depois das revelaçóes de Edward Snowden sobre a abrangência das atividades da Agência Nacional de Segurança (NSA) dos EUA e o grau de cooperação da agência com as grandes empresas de tecnologia (Chenou and Radu, 2014). Houve então uma forte politização da gestão da rede e um aprofundamento das discussóes acerca do modelo de GI (Scholte, 2017). O discurso libertário e antiestatalista inicial, denunciado como retórica para encobrir a influência do governo dos
EUA, deu lugar a uma disputa retórica entre multissetorialismo e intergovernamentalismo, com a crescente hegemonia do primeiro, em grande parte impulsionado pelo próprio governo dos EUA (Radu, Chenou, \& Weber, 2014).

Com efeito, a gestão de nomes e domínios, assim como o desenvolvimento dos protocolos e códigos da rede se deram sob forte influência de empresas privadas e atores não-governamentais (a comunidade de cientistas e engenheiros), os quais desempenhavam papéis cruciais como operadores e intermediários de informaçóes. Desde o princípio, aos Estados coube, de fato, um papel coadjuvante (Raymond \& Denardis, 2015). A decisão dos EUA de abrir mão da função de supervisor da GI, por meio da NTIA, se deu sob a condição de que outros Estados náo assumissem influência. Como consequência um tanto inusitada desse processo de negociação complexo hegemonizado pelos EUA, a GI passou a ser descrita (e desenhada) como o resultado de um processo dinâmico em que diferentes stakeholders interagem e alteram continuamente as regras e seus processos de formulação (Flyverbom \& Bislev, 2008; J. A. Scholte, 2017; Sylvan, 2013).

O significado do modelo multissetorial reside, exatamente, no fato de ele ser capaz de servir de descrição para um arranjo em que cada um desses atores se compreende como parte do processo, mesmo que em algum momento eles possam ter frustradas suas expectativas (Flyverbom \& Bislev, 2008). E apesar de todas as transformaçóes, com a crescente participação dos Estados e de organizaçôes internacionais ao longo dos últimos 20 anos, o multissetorialismo na GI parece funcionar como uma retórica altamente eficiente para legitimação de maneira alternativa ao modelo tradicional de regulação hierárquica centralizada baseada na soberania do Estado, num ambiente em que esta dificilmente se legitimaria (Casini, 2014).

"Governança" é o conceito utilizado para descrever formas de regulação resultantes de uma desagregação das fontes de autoridade (Rosenau, 2007; Porter, 2008) que tornam menos claras as fronteiras entre o Estado (como poder público) e a sociedade civil regulada (Hall \& Biersteker, 2002b; Rhodes, 2012). No contexto da chamada 
"transição para a governança”" (Rhodes, 1996), a autoridade não seria mais exercida de forma direta por um ator hierárquico único e central. Em lugar disso, a autoridade resultaria da deferência de uma miríade de atores às suas pretensões recíprocas de exercer tal autoridade (Stoker, 1998; Krisch, 2017). Isso pode se dar por conta da qualificação técnica, da legitimidade de certo ator em uma rede, ou mesmo por conta da capacidade deste ator em mobilizar recursos econômicos, políticos ou tecnológicos (poder, dinheiro e saber) (Porter, 2008) - o que deixa claro que "governança” não necessariamente implica "consenso".

As características das novas formas de exercício da autoridade na "era da governança" parecem ser a informalidade, a multiplicidade de fontes e atores a participar dos processos regulatórios, a ausência de estruturas oficiais únicas e o dinamismo da regulação, a qual passa a resultar de um contínuo processo de adaptação cognitiva dos atores às demandas da área regulada (Krisch, 2017). Ao lado dos atores de mercado, que adaptam suas expectativas de investimento e negócio num mercado transnacional (Rhodes, 1996), aumenta também a importância de técnicos e especialistas, pois são eles que dispóem do conhecimento e do treinamento muitas vezes necessário para articular e tornar congruentes expectativas incongruentes, possibilitando a coordenação típica da regulação por meio da governança (Kennedy, 2005; Drori and Meyer, 2006). O conhecimento especializado se torna assim mais uma fonte de autoridade (Quack, 2016). Todos esses fatores passam a interagir com os Estados em novos arranjos, produzindo uma nova dinâmica social e novas formas de autoridade.

Essa descrição coincide, de maneira evidente, com a evolução da GI e o papel de técnicos e empresas na gestão dos recursos críticos. E o multissetorialismo, como discurso e como prática, parece oferecer um exemplo claro de como essas transformaçôes se tornam operacionais no interior de regimes de governança. Nosso estudo de quatro regimes de governança nacionais dos ccTLDs (Brasil, Argentina, Colômbia e México) tentará oferecer elementos para que possamos compreender melhor o significado desse modelo.

\section{A governança latino-americana da internet $\mathrm{e}$ os domínios de topo territoriais (ccTLDs)}

O sistema de nomes de domínios (DNS), gerido pela ICANN, é o que possibilita com que cada endereço na rede mundial seja único e, portanto, acessível. Crucial para a sua administração é a definição dos domínios de topo - ou top level domains (TLDs) -, como o .com, o .edu ou o .net, os chamados TLDs genéricos. Além destes, existem os domínios de topo de código de país (ccTLDs) que foram atribuídos por Jon Postel, de acordo com duas letras (.br, .ar, .uk), antes mesmo da criação da ICANN, ainda na década de 1980, a partir de uma lista de 243 países disponibilizada pela International Standardization Organization (ISO).

Jon Postel delegava a atribuição de ccTLDs para atores-chave. Esses atores, por sua vez, poderiam representar um governo, uma universidade, uma associaçấo privada ou mesmo uma empresa não havia uma regra geral ou restrições para a delegação, apenas a ordem de chegada e a confiança pessoal. Critérios mais claros, a ênfase no caráter nacional e a necessária aprovação dos governos vieram posteriormente, com a criação da ICANN e o progressivo envolvimento do GAC, o Governmental Advisory Committee da Corporação, depois que muitos ccTLDs já haviam sido delegados. Assim, houve grande autonomia para a evolução dos respectivos regimes de gestão dos ccTLDs, sem que houvesse um modelo único de gestão nos diferentes países. Na verdade, conforme um entrevistado destacou, "muita gente pode discordar sobre qual modelo é melhor (para os ccTLDs) e muitas vezes se trata na verdade de um acidente histórico no país" (entrevistado XV, tradução própria).

Tal independência entre os modelos é fortalecida pelo fato de que, enquanto os domínios genéricos (como o .com e o .net) estão diretamente submetidos à ICANN, os ccTLDs não são objeto de quaisquer obrigaçóes contratuais relacionadas à Corporação, restando à ICANN apenas o papel de gerenciamento dos arquivos da zona raiz do DNS perante os ccTLDs.

A principal diferença entre um ccTLD e os demais domínios reside nos seus objetivos principais. Se um domínio genérico, como por exemplo 
o .com, existe para suprir uma demanda (a de usuários que querem criar sites com tal domínio) e gerar lucro, os ccTLDs, nas palavras de um entrevistado do .br, "atendem à demanda da comunidade local por uma identidade nacional”, como no caso do .ar, e/ou "trazem receita para o país focando no mercado global" (entrevistado IV), como é o caso do .co. Essas duas finalidades dos ccTLDs estão presentes nos casos analisados no artigo e são refletidas na pluralidade de arranjos institucionais em cada um deles.

A interação multissetorial em cada contexto gera assim uma pluralidade de arranjos, espaços de autoridade e soluçóes. Essa diversidade faz com que não seja natural que um país administre ou detenha posse sobre o código de duas letras. É até hoje comum e aceitável para a comunidade da internet que os ccTLDs possam ser administrados e vendidos por entidades que não tenham qualquer relação formal - financeira ou legal - com o Estado em questáo, sendo o multissetorialismo usado muitas vezes como recurso de autoridade para assegurar trajetórias e modelos de governança distintos.

A seguir, reconstruímos a trajetória de quatro regimes de gestão de ccTLDs. Esses quatro países foram escolhidos por terem trajetórias extremamente distintas, embora façam parte do mesmo contexto regional e tenham obtido os ccTLDs em um período parecido.

\section{Argentina}

O “. ar" foi o primeiro ccTLD a ser delegado entre os quatro casos analisados. Em 1985, um grupo de professores, graduados e estudantes do Departamento de Informática da Faculdade de Ciências Exatas e Naturais (FCEN) da Universidade de Buenos Aires começou a trabalhar no desenvolvimento de redes eletrônicas no país. Foi a partir desse grupo que foi criada a Rede Acadêmica Nacional (RAN), onde os primeiros testes de transmissão de dados ocorreram. Em 1986, foi dado início a um projeto do Programa das Naçóes Unidas para o Desenvolvimento (PNUD) com o objetivo de modernizar e informatizar o Ministério de Relaçóes Exteriores do país. Nesse contexto, alguns pesquisadores da RAN foram integrados ao Ministério para trabalhar nesse tema. E, como resultado dessa associação, o Ministério conseguiu em 1987 a primeira comunicação internacional via e-mail da Argentina.

No mesmo ano, o ".ar" começou a operar sob a direção de informática da chancelaria. Segundo Aguerre (2015), o processo de delegação do ".ar" foi mais fruto de casualidade do que uma política estratégica de governo, e resultou da presença de "engenheiros apaixonados pelo emergente fenômeno de redes" (p. 211) trabalhando dentro da chancelaria. Tal processo evidenciou o conhecimento especializado dos engenheiros como uma justificativa para sua posterior autoridade partícipe da gestão do domínio.

Após 24 anos da delegação, em 2011, um decreto presidencial transferiu a responsabilidade pela gestão do .ar da chancelaria para a Direção Nacional de Nomes de Domínio (NIC.ar), órgão criado dentro da Secretaria Jurídica e Técnica da Presidência da Nação. De acordo com Aguerre (2015), essa mudança de direção deu um status administrativo mais central para o ccTLD dentro da burocracia, ao mesmo tempo em que proporcionou maior autonomia para que o NIC.ar desenvolvesse suas funçôes técnicas, passando a ser um ator com direitos próprios sobre políticas de internet perante o Estado e a comunidade da internet argentina (Aguerre, 2015).

Dando prosseguimento ao gradual aumento de interesse por parte do governo na formulação de políticas para a internet, também foi criada a Comissão Argentina de Política de Internet (CAPI) através da Resoluçáo n. 13 de 2014. A CAPI foi estabelecida como um espaço formal para a coordenação intragovernamental em relação a assuntos de internet. A Comissão passou a articular o trabalho de oito agências envolvidas com diferentes camadas da política interna para a rede (Aguerre \& Galperin, 2015).

A resolução de criação da CAPI reconhecia "o modelo de múltiplas partes na 'Governança da Internet" e dispunha "que, para articular a participação dos diferentes atores para desenhar uma estratégia nacional sobre a internet e sua governança, é necessária e oportuna a criação de um grupo de trabalho" (Argentina, 2014). Era assinalada, pela primeira vez, a importância da inserçâo de múltiplos atores na GI local em uma resolução do governo. Contudo, a Comissão se reuniu apenas uma vez, desde então, com setores da academia, do setor privado e da sociedade 
civil, e as expectativas de que a CAPI pudesse funcionar como uma entidade multissetorial não foram plenamente cumpridas. A Comissão funcionou mais como mecanismo de coordenação institucional interno do governo, e a declaração de intençôes multissetorial serviu mais como regra simbólica frente à comunidade especializada.

Para ampliar o debate sobre internet no país e aumentar a participaçáo dos múltiplos atores a partir da ideia de multissetorialismo, o NIC.ar passou a organizar, desde 2015, o Internet Recorre - evento que leva palestras sobre GI para o interior da Argentina e é realizado em cooperação com entidades da sociedade civil, do setor privado e do governo ${ }^{8}$. Além disso, cabe destacar que, a partir de 2016, a Argentina passou a ter um Fórum de Governança de Internet nacional, à semelhança do fórum global, para debater coletivamente os desafios enfrentados pela comunidade. A organização do Fórum é de responsabilidade de um comitê multissetorial, criado de forma autônoma, e composto por representantes de setores interessados. Em 2017, o NIC. ar também passou a promover as Charlas Debate sobre Gobernanza de Internet, seminários periódicos que contam com a participação de distintos setores: mais um mecanismo autodeclarado multissetorial com envolvimento direto do ccTLD.

O caso argentino é interessante por ser o que apresenta menos características multissetoriais na gestão cotidiana do domínio e mais submissão direta à gestão estatal. Com efeito, se o Estado é parte fundamental de todos ccTLDs, dada a evidente ligação de tais recursos com seus territórios, no caso argentino tal ligação é ainda mais evidente, posto que o ccTLD está sob sua burocracia. Ainda assim, conforme apontado por um entrevistado da Argentina:

Todo ccTLD tem que se vincular de alguma forma a certas estratégias [...] com o governo. Isso não significa que tenha de depender, se submeter. [...]

Porque a prática tem a ver com diferentes atores e o governo é só mais um (entrevistado II).

Ou seja, mesmo que o domínio seja delegado a um órgão de Estado, necessita de alguma forma de reconhecimento pelos outros atores da comunidade local da internet. E o NIC.ar busca promover iniciativas e eventos que deem espaço aos diversos setores. O multissetorialismo é compreendido de forma distinta por cada um dos atores envolvidos, que tendem a ver sua importância como mais determinante. Ainda assim, o multissetorialismo funciona como mecanismo de convergência para a formulação das políticas e como retórica legitimatória, permitindo também uma adaptação dinâmica entre os distintos interesses, mesmo que haja forte heterogeneidade de poder entre eles, sobretudo em favor do Estado argentino.

\section{Brasil}

No Brasil, Jon Postel delegou o ".br" à equipe que trabalhava pelo estabelecimento da conexão do país à internet na Fundação de Amparo à Pesquisa do Estado de São Paulo (Fapesp), na figura do pesquisador Demi Getschko. Posteriormente, o Governo Federal criou a Rede Nacional de Pesquisa (RNP), ligada ao Conselho Nacional de Desenvolvimento Científico e Tecnológico (CNPq), com o intuito de disseminar o uso da internet para fins educacionais e sociais. A gestão do ccTLD continuava sob responsabilidade do grupo de pesquisa de Getschko, mas foi a RNP que criou o ambiente para que, em 1991, surgisse o primeiro backbone brasileiro, a rede principal pela qual os dados de todos os clientes da internet passam, conectando à época universidades, centros de pesquisa e laboratórios tecnológicos (Adachi, 2011).

Enquanto a gestão do ".br" permanecia na Fapesp, entre 1994 e 1995, os ministérios das Comunicaçôes e da Ciência e Tecnologia lançaram um projeto para implantar no país uma rede de internet para além daquela voltada a fins acadêmicos. Com isso, a RNP foi expandida e reconfigurada e a Empresa Brasileira de Telecomunicaçóes (Embratel), então estatal, começou a iniciar testes comerciais com a internet.

A definição da internet como um serviço de valor adicionado e não como um serviço típico de telecomunicaçóes pelo governo apaziguou os temores de que a administração da rede fosse feita da mesma forma que o restante do setor. Em consequência, foi publicada a Portaria Interministerial 147 de 31/05/1995, criando o Comitê Gestor da 
Internet no Brasil (CGI), que separou a regulação da internet da telecomunicação. De acordo com Carvalho (2006), a publicação da portaria se deu em um contexto em que os Ministros da Ciência, Tecnologia e Comunicações possuíam relações pessoais próximas com os principais atores da RNP, incluindo acadêmicos e representantes do incipiente setor privado (Carvalho, 2006).

Talvez por isso, o CGI foi pensado como um projeto a ser organizado a partir de um modelo multissetorial, possuindo, já em sua fase inicial, cadeiras para distintos stakeholders em sua gestão. No entanto, num primeiro momento, entre 1995 e 2003, ele estava sob maior controle governamental, já que era o governo que autorizava os nomes dos representantes da sociedade civil, da academia e do setor privado. Por outro lado, o grupo de pesquisa da Fapesp permanecia responsável pela administração operacional do “.br". Ou seja, o operador dos recursos críticos nacionais da internet era uma instituição eminentemente acadêmica, tomando na prática decisóes cruciais sobre a gestão do domínio (Aguerre, 2015).

Considerando a importância dos serviços associados à gestão do “.br" e sua monetização, surgiu então uma pressão pela institucionalização da função até então exercida pela Fapesp. Ao mesmo tempo, consolidava-se a ideia de que seria preciso formalizar eleiçóes para as cadeiras não-governamentais do CGI, em um esforço de reduzir sua dependência das políticas de governo. Em setembro de 2003, foi editado o Decreto Presidencial 4.829, que estabeleceu eleiçóes para as cadeiras dos setores não-governamentais. Ao mesmo tempo, o número de cadeiras para representantes não-governamentais aumentou paulatinamente até alcançar o número de 11 representantes escolhidos por seus pares em eleiçóes trienais, mais 9 cadeiras destinadas a representantes de órgãos governamentais, e uma cadeira para representante civil de notório saber indicado pelo Ministro da Ciência e da Tecnologia, cargo historicamente ocupado por Demi Getschko (Anastacio, 2015).

Nesse contexto, foi criado o NIC.br (Núcleo de Informação e Coordenação do Ponto BR), associação civil sem fins lucrativos, ou seja, uma entidade de direito privado, que atua como articuladora do CGI, executando e prestando assistência às suas decisões e oferecendo recomendações. Na prática, é o NIC.br quem cuida da gestão efetiva do ".br", exercendo um papel similar ao que era atribuído à Fapesp, mas com total autonomia "administrativa, patrimonial e financeira” (NIC.br, 2005, estatuto).

O ccTLD brasileiro apresenta um modelo de governança que se autodefine como fundamentalmente multissetorial, abarcando distintos setores tanto no CGI como no seu braço administrativo, o NIC.br. As 11 cadeiras de setores não-governamentais do CGI são definidas por meio de um processo eleitoral trienal: o chamado terceiro setor possui 4 vagas; a comunidade científica e tecnológica, 3; e o setor empresarial, 4 (Anastacio, 2015). Já o NIC. br é composto por uma Assembleia Geral, por um Conselho de Administração formado por membros de diversos setores, por uma Diretoria Executiva e por um Conselho Fiscal. Há também em sua estrutura grupos de trabalho e Câmaras de Consultoria criadas para debater assuntos específicos.

Desde 2011, o CGI promove o Fórum da Internet no Brasil, que funciona como uma atividade preparatória para o fórum global (IGF). Por meio dele, o CGI.br convida os diversos setores da GI nacional a opinarem sobre questóes relevantes para a GI local. O Comitê realiza, também anualmente, o Seminário sobre Privacidade e Proteção de Dados Pessoais, além de Escolas de Governança da Internet - tanto em uma versão geral, como em uma versão destinada a juízes e advogados.

Cabe destacar que, em agosto de 2017, o Ministério da Ciência, Tecnologia, Inovaçóes e Comunicações (MCTIC), sob o governo Temer, abriu uma "Consulta Pública acerca da modernização da estrutura de governança da Internet brasileira" que gerou severas suspeitas de que o Estado tentaria assumir o controle do CGI, ameaçando o desenho vigente do modelo multissetorial (Mueller, 2017). Após embates entre o governo, membros do Comitê e entidades da sociedade civil, amparados por ampla pressão internacional, iniciou-se uma etapa de discussão no próprio CGI, por meio da promoção de uma consulta pública e de assembleia realizada no Fórum da Internet no Brasil em 2017 (resolução 031, de 2017, CGI.br). A mobilização multissetorial aparentemente evitou que 
houvesse mudanças. E mesmo o recente Decreto 9.759/2019, do governo Jair Bolsonaro, que extinguiu todos os colegiados e conselhos da Administração Federal que não houvessem sido criados por lei, preservou o CGI.br. Mais uma vez, houve forte reação dos atores chave da comunidade da internet, a começar pelo próprio Demi Getschko.

Mesmo frente a possíveis alteraçóes no processo de gestão, o poder de influência dos setores empresariais, acadêmicos e de ativistas foi e ainda é peça fundamental na gestão dos recursos críticos no país. O modelo multissetorial brasileiro é alvo de constante disputa entre stakeholders, como evidenciado pelo processo iniciado com Temer. Ainda assim, o maior trunfo do CGI para assegurar sua autoridade é justamente sua gestão declaradamente multissetorial.

México

O “.mx" nasceu em 1989, dentro do Instituto Tecnológico e de Estudos Superiores de Monterrey (ITESM), universidade privada responsável pela primeira conexão do México à internet. Outras universidades do país também estavam envolvidas em iniciativas de acesso à rede. Ao longo do tempo, estabeleceram-se três frentes para a internet no país. A primeira era a Rede da Universidade Nacional Autônoma do México, UNAM, na figura de seu Instituto de Astronomia. A segunda era a iniciativa MEXNET, que abarcava universidades com conexões independentes e o Tecnológico de Monterrey (ITESM), com a participação do Conselho Nacional de Ciência e Tecnologia (Conacyt) - interessado, entre outras coisas, em avançar a conexão à rede para o governo mexicano. E a terceira era a RUTYC (Rede de Universidades Técnicas e Centros), em que universidades públicas foram congregadas.

Em 1993, a RUTYC foi extinta, cabendo à MEXNET e à UNAM servirem como centros para a gestáo da internet no país. De acordo com Aguerre e Galperin (2015), o ambiente era de rivalidade e desacordo entre os centros acadêmicos, inclusive devido à competição pelo apoio financeiro governamental.

Até 1992, nenhuma administração dedicada e extensiva do ccTLD era necessária, por haver poucos nomes de domínio atrelados à sigla - a maioria utilizada por centros de pesquisa e universidades. A partir de 1995, ao mesmo tempo em que ocorreu uma expansão comercial do uso do “. $m x$ ”, acompanhando a própria expansão da internet comercial no país, o ITESM, que contava com a participação da Conacyt, foi oficialmente indicado como NIC. $\mathrm{mx}$ (Network Information Center do México).

O NIC.mx possuía apenas um conselho diretor até 1997, promovendo ocasionalmente algumas Reunión(es) de Información y Retroalimentación de NIC México, que congregavam clientes com o objetivo de informá-los acerca do ambiente da internet e de colher sugestóes e críticas sobre o serviço prestado. Já em 2001, o NIC.mx estabeleceu formalmente um Comitê Consultivo Externo, um órgão de consulta aberto à participação dos distintos setores para discutir temas estratégicos e fazer recomendações, também visando a impulsionar o desenvolvimento da internet no país.

Esse Comitê é composto por até 15 membros oriundos de três setores: a indústria, a academia e o governo. Os membros participam como pessoas físicas e são selecionados a partir de um processo em que o Diretor Geral do NIC.mx propóe ao Conselho de Administraçáo da entidade uma lista de candidatos para aprovação ou rejeição (diretrizes do Comitê, site do Registro.mx). A maior parte das discussōes do Comitê ocorre através de listas de correio eletrônico com reunióes presenciais ocasionais.

Além disso, em 2012, o governo mexicano criou a Estratégia Digital Nacional encabeçada pelo gabinete da Presidência da República, com o intuito de estabelecer uma gestâo multissetorial no México para tratar de assuntos para além dos recursos críticos. Segundo o governo, a estratégia foi fruto de "meses de estudo, de trabalho e de reflexão multissetorial sobre o México Digital que queremos alcançar, onde a troca de ideias e o diálogo foram os eixos norteadores" (México, 2013, p. 7).

A iniciativa foi paralela ao estabelecimento informal de um "grupo de iniciativa" no ccTLD ". $m x$ ” com a junção de distintos setores para debater temas de internet de interesse nacional. O NIC.mx, apoiado pelos diversos setores, incluindo o governo, convocou inicialmente dois representantes por setor mediante convites pessoais, não oficiais e não obrigatórios. O grupo gradualmente 
se consolidou em uma organização multissetorial composta por cinco setores: academia, sociedade civil, comunidade tecnológica, operadores e governo, e trabalha por meio de discussóes em listas e decisóes baseadas no consenso (Aguerre \& Galperin, 2015). O grupo conseguiu organizar, ainda em 2013, os "Diálogos sobre Governança da Internet", espécie de fórum da internet nacional.

No caso mexicano, a delegação e a popularização do domínio “.mx” ocorreu no contexto acadêmico, fomentado também por recursos governamentais oriundos do Conacyt. O modelo multissetorial parece ter se tornado a regra legitimatória do processo de governança do ".mx", com o interesse dos diversos setores devendo ser ao menos considerado na gestão do ccTLD.

\section{Colômbia}

Entre os casos analisados, a Colômbia foi o último dos países a estabelecer seu operador de ccTLD. Em 1991, o Centro de Computação da Universidade dos Andes (Uniandes), entidade privada sediada em Bogotá, conectou a Colômbia pela primeira vez à internet com base no protocolo TCP/IP, com a ajuda da empresa Telecom e do Instituto Colombiano de Fomento para a Educação Superior (ICFES), parte do Ministério da Educação do país. Nesse momento, a Uniandes passou a administrar o ".co". O domínio foi usado para comunicaçóes internas até o ano de 1994, quando a Colômbia efetivamente conseguiu se conectar à internet para além dos centros acadêmicos, novamente através da Universidade dos Andes em cooperação com universidades espalhadas pelo país. Com isso, o uso comercial do “.co" também se intensificou.

Dez anos após a delegação, em 2001, a Uniandes passou a considerar a possibilidade de comercializar o domínio como uma alternativa aos domínios genéricos, visto que o ".co", pela sua proximidade com o ".com" e ligação com os termos em inglês company e coorporation, teria bom potencial de mercado (IANA, .co report, 2009). No entanto, o governo da Colômbia opôs-se a essa iniciativa, defendendo que a universidade, uma entidade privada, não tinha competência regulatória sobre o ccTLD.
Assim, no final de 2001, a então Ministra das Comunicaçôes solicitou ao Conselho de Estado que analisasse a natureza pública do domínio ".co", cuja administração havia sido concedida à Universidade pela ICANN e por Postel. A análise deveria responder: a) se o domínio ".co" seria um recurso público; b) caso fosse, se seria um recurso ligado às telecomunicações; e, c) se ele estivesse vinculado às telecomunicações, quem deveria lucrar com sua comercialização. A conclusão apontada pelo governo foi de que o ".co" é de interesse público, está relacionado às telecomunicaçóes e, portanto, seria de competência do Ministério de Tecnologias da Informação e das Comunicações (MINTIC) (IANA, .co report, 2009).

Em resposta à análise do Conselho de Estado, a Uniandes escreveu à ICANN afirmando interesse em abandonar os planos de comercialização do domínio e suspender sua responsabilidade de operação sobre o ccTLD. Em maio do mesmo ano, o governo emitiu Resolução dispondo que a manutençấo e desenvolvimento do ".co" devem ser planejados, regulamentados e controlados pelo Estado através do MINTIC (IANA, “.co” report, 2009). Em cartas trocadas com a ICANN, o Ministério afirmou que aceitaria a Uniandes como administradora do ccTLD, desde que ela cumprisse a regulamentação. A universidade, por sua vez, estava em posição de atrito com o governo, sobretudo por sentir-se desconsiderada nas decisóes tomadas até então, e o país viu-se em meio à proliferação dos debates sobre o domínio, inclusive dentro do parlamento.

Os debates públicos prosseguiram até que o governo promulgou a Lei 1065 de 2006, regulando a administração do serviço de registro de nomes de domínio. Segundo a lei, essa atividade é de competência do MINTIC, que poderia delegar a administração para terceiros em um contrato de até 10 anos, aberto para uma única renovação. A partir de então, um período de consulta de três anos começou, com debates dentro do Congresso colombiano, mas também por meio de plataformas de participação social, para definir como a lei seria aplicada. Em maio de 2009, um processo de licitaçâo pública foi iniciado para definir o operador. Já em julho, relatório de avaliação preliminar sobre os 
licitantes foi publicado e aberto para comentários das partes interessadas. A empresa vencedora foi a .CO Internet SAS, criada especificamente com o fim de potencialmente administrar o ".co" (IANA, “.co" report, 2009).?

A Uniandes deixou de prestar os serviços de gestão do ccTLD em 2010, e a ICANN redelegou o ".co" para o MINTIC, definindo a concessionária .CO Internet SAS como sponsoring organization. Em 2014, a .CO Internet SAS foi adquirida pela Neustar por US\$ 109 milhôes e tornou-se uma subsidiária integral da empresa estadunidense. A Neustar já servia como suporte de infraestrutura para o ".co", e é a dona de outros domínios como o ".us" e o ".biz".

Dessa forma, o modelo de governança do ".co" é um modelo de terceirizaçấo: o ccTLD é delegado ao Ministério das Comunicaçóes, mas executado por empresa privada concessionária (Colômbia, 2008a). Mudanças nas políticas de venda dos domínios precisam ser publicadas pelo MINTIC, mesmo que a partir de decisōes oriundas do conselho administrativo da empresa e posteriormente debatidas pela administração pública. Ademais, a empresa contratada paga uma contraprestação em conformidade com seu faturamento para um fundo nacional.

Apesar de orientado claramente por uma parceria público-privada com finalidade econômica, o modelo colombiano também tentou introduzir na sua gestão um mecanismo de controle multissetorial. Para além dos amplos debates públicos ocorridos até a re-delegação, ainda em 2008, antes da licitação para a escolha do operador, foi criado um Comitê Assessor com o objetivo de assistir ao Estado na formulação das políticas para o ccTLD. Segundo a Resoluçáo 1.652 de 2008 do MINTIC, a empresa contratada deveria "implementar e custear as políticas e/ou atividades para assegurar o respaldo da comunidade local da internet de acordo com os alinhamentos do Comitê Assessor" (Colômbia, 2008a). Resoluçāo posterior, número 1.250 de 2008, definiu que tal comitê visaria a "analisar as necessidades da comunidade da internet da Colômbia e as tendências na matéria de políticas para os ccTLDs a nível mundial" (Colômbia, 2008b, Artigo 3).

Ou seja, mesmo que o Estado colombiano tenha assegurado uma autoridade hierárquica na ges- tão do domínio, houve o estabelecimento de um arranjo multissetorial com a definição em legislação da importância da abertura do domínio para a comunidade local e para as tendências da governança global da internet. Atualmente, o Comitê é composto pelo Ministro, Vice-ministro e o Diretor de Comunicaçóes do MINTIC e pelo Vice-ministro de Comércio. Também são convidados a Uniandes, a Direção Nacional de Direitos Autorais, representante do Setor Empresarial, representante de professores universitários, a Câmara de Comércio Eletrônico, a Associação Colombiana de Usuários de Internet, representante de empresa de venda de domínios nacional e a própria .CO Internet SAS (Colômbia, 2008b).

Outra iniciativa multissetorial foi a criação da "Mesa Colombiana de Governança da Internet". O projeto foi iniciado informalmente em 2012 e, desde entáo, promove reunióes bimestrais em diferentes cidades. A iniciativa possui também uma lista de e-mails para promover a discussão continuada e a participação é aberta ao público. Todas as atas das reuniōes são publicadas na internet e construídas coletivamente. A Mesa foi ainda responsável por iniciar a criação do Fórum de Governança da Internet colombiano, equivalente ao IGF global. De forma que o modelo colombiano tenta introduzir distintas versóes de multissetorialismo, ao menos como forma de legitimar sua regulaçáo frente à comunidade local da internet.

\section{O multissetorialismo como regra de autoridade na governança dos ccTLDs}

Os quatro ccTLDs abordados fazem uso do léxico multissetorial como modelo de integração de distintos setores interessados na GI, dentro e fora do Estado, em arranjos formais e informais (Almeida, Getschko, \& Afonso, 2015; Raymond \& Denardis, 2015). Além disso, a tentativa de inserção de outros setores no dia a dia dos ccTLDs parece ser importante mesmo para aqueles que não possuem o multissetorialismo estabelecido em normas reconhecidas pelo Estado, como ocorre no Brasil e na Colômbia. No México, por exemplo, um entrevistado afirmou que, quanto ao envolvimento do 
Estado, os processos de diálogo podem ser "muito enriquecedor(es) para eles (membros do governo), porque às vezes eles não estão tão conscientes dos desafios que um ccTLD tem" (entrevistado VII). Mesmo no caso da Argentina, conforme outro entrevistado, "quando falamos de governança, pensamos que todos os atores têm que estar presentes" (entrevistado II, tradução própria) e não apenas a burocracia a cargo do ccTLD.

Segundo a definição mais comum, o modelo multissetorial compreende a administração da rede pelo governo, pelo setor empresarial e pela sociedade civil, segundo seus respectivos papéis (Chenou, 2011). A definição do que sejam os "respectivos papéis" é, contudo, deixada em aberto. A função de cada um desses atores depende do contexto e do momento em que se observa cada um dos regimes da GI, o que resulta de fatores técnicos, como a necessidade de padronização da comunicação, de fatores econômicos, como o financiamento da infraestrutura e sua explosão comercial e, obviamente, fatores políticos, como o interesse dos Estados e de outros setores da GI e sua capacidade de realizá-los. Esses papéis são também objeto de disputas e contestação, seja por parte do poder público seja por parte do setor privado (empresarial ou não).

Maciel nota que o modelo multissetorial é percebido pelos atores como eficiente para a GI por representar abordagem mais rápida e simples para a regulação e a formulação de políticas públicas para a rede (Maciel, 2014). Com efeito, "[a Internet] distribui-se fisicamente por distintas jurisdiçôes soberanas e tem como 'portas de entrada' entidades públicas e privadas, com ou sem fins lucrativos, que ofertam interconectividade e acesso à rede" (Canabarro, 2014, p. 27). O multissetorialismo na GI seria assim um caso de difusão de poder e autoridade, que não necessariamente anula a presença e interferência dos Estados, mas que, dependendo dos Estados, potencializa a ação de atores privados que, em alguns casos, possuem mais expertise e legitimidade perante os pares para lidar com temas altamente complexos e extremamente específicos. A especialização regulatória se retroalimenta e favorece a emergência de arranjos regulatórios que dão mais poder ao setor privado.
Certamente, os arranjos multissetoriais são diversos e dinâmicos. E é frequente a existência de conflitos entre os interesses privados (empresariais, ou da sociedade civil) e as estratégias estatais de regulação. No caso colombiano, por exemplo, houve disputas profundas entre estratégias empresariais de exploração comercial dos topos de domínio e as estratégias estatais de difusão da internet. No caso brasileiro, o modelo baseado em uma entidade privada sem fins lucrativos e multissetorial, pioneiro na GI mundial, também apresenta resistência às tentativas do Estado em avançar na regulação do setor e mudar a divisão de poder no Comitê em favor dos interesses do governo.

Em todos esses casos, é possível perceber também certa dependência de trajetória. A presença privada e a gestão de negócios empresarial são marcas dos modelos colombiano, bem como do mexicano, ainda que este retenha sua ligação com a academia. Da mesma forma, o papel do setor acadêmico continuou sendo importante no modelo brasileiro e a burocracia estatal argentina segue com espaço relevante na GI local. Nesse sentido, pode-se afirmar que o modelo multissetorial tem uma plasticidade que oferece espaço para uma diversidade de arranjos em que setores privados e setores estatais podem exercer diferentes níveis de autoridade conforme especificidades contextuais (DeNardis, 2014). A resolução de potenciais conflitos depende do contexto e da trajetória dos regimes, e varia conforme a inclusão de atores e o peso desses atores no respectivo arranjo. E como apontam Raymond e Denardis (2015), os arranjos multissetoriais da GI são normalmente baseados em uma poliarquia heterogênea em que um dos setores, ou grupo de atores, costuma ter mais peso que o outro na definição da regulação.

Como vemos no quadro abaixo, a diversidade de origens dos casos estudados levou a uma diversidade de arranjos posteriores. Apesar disso, eles apresentam uma convergência semântica em torno do multissetorialismo e uma forte presença de atores privados na definição da regulação da rede. Isso não diz, de antemão, qual setor é preponderante e qual o modelo de negócios que é o vigente em cada regime. Nesse sentido, eles apresentam uma certa variedade. 
Nos quatro casos, há algum envolvimento do Estado na gestão dos ccTLDs, seja por meio da elaboração de normativas posteriores à delegação inicial dos domínios a entidades independentes (os casos brasileiro, a Demi Getschko, da Fapesp, e colombiano, a Uniandes), seja graças à inclusão da gestão na própria burocracia estatal (como no caso argentino), ou pelo reconhecimento do operador do ccTLD como ator importante para a elaboraçáo de políticas gerais para a internet (o caso mexicano). Ainda assim, o multissetorialismo funciona, em todos os casos, como mecanismo, ao menos nominal, para a elaboração de políticas e tomada de decisão, e também como regra de autoridade, criando uma semântica constitucional para a GI amparada no multissetorialismo (Flyverbom \& Bislev, 2008). Tal semântica é demonstrada no caso dos ccTLDs estudados que, apesar das evidentes diferenças históricas e institucionais, convergem na mobilização do discurso multissetorial.

A comunidade da internet parece aceitar os ccTLDs como recursos independentes, em que há maior espaço para a interferência estatal ou para possibilidade de criação de arranjos não subordi-

Quadro 1

Comparativo das Características dos Operadores

\begin{tabular}{|c|c|c|c|}
\hline \multicolumn{4}{|c|}{$\begin{array}{l}\text { HISTÓRICO } \\
\text { quem é e foi o responsável pelo ccTLD? }\end{array}$} \\
\hline ARGENTINA & BRASIL & MÉXICO & COLÔMBIA \\
\hline $\begin{array}{l}\text { BUROCRACIA ESTATAL } \\
\text { da chancelaria para a } \\
\text { Presidência da Naçấo }\end{array}$ & $\begin{array}{l}\text { ENTIDADE } \\
\text { MULTISSETORIAL } \\
\text { amparada em entidade sem } \\
\text { fins lucrativos (NIC.br), } \\
\text { criada em } 2005\end{array}$ & $\begin{array}{l}\text { UNIVERSIDADE } \\
\text { PRIVADA } \\
\text { com a criação da empresa } \\
\text { NIC.mx }\end{array}$ & $\begin{array}{l}\text { EMPRESA PRIVADA } \\
\text { da Uniandes para o } \\
\text { MINTIC, com concessão à } \\
\text {.CO INTERNET SAS }\end{array}$ \\
\hline \multicolumn{4}{|c|}{$\begin{array}{l}\text { NORMATIVA NACIONAL VIGENTE } \\
\text { bá legislação especifica sobre o ccTLD? }\end{array}$} \\
\hline Lei e resoluçóes ministeriais & $\begin{array}{l}\text { Portaria interministerial e } \\
\text { decreto presidencial }\end{array}$ & Não possui & Lei e resoluçôes ministeriais \\
\hline \multicolumn{4}{|c|}{$\begin{array}{l}\text { MODELO DE GOVERNANÇA } \\
\text { bá participaçấo direta ou indireta de outros stakeholders? }\end{array}$} \\
\hline ARGENTINA & BRASIL & MÉXICO & COLÔMBIA \\
\hline \multirow[t]{2}{*}{$\begin{array}{l}\text { INDIRETA } \\
\text { multissetorialismo em } \\
\text { atividades paralelas (CAPI, } \\
\text { reunióes esporádicas e eventos } \\
\text { de GI) }\end{array}$} & $\begin{array}{l}\text { DIRETA } \\
\text { formaçäo de colégio eleitoral } \\
\text { e de conselho composto pelos } \\
\text { stakeholders }\end{array}$ & $\begin{array}{l}\text { DIRETA } \\
\text { comitê consultivo externo de } \\
\text { stakeholders formado pelo } \\
\text { próprio NIC.mx }\end{array}$ & $\begin{array}{l}\text { DIRETA } \\
\text { comitê assessor de } \\
\text { stakeholders estabelecidos por } \\
\text { normativa }\end{array}$ \\
\hline & $\begin{array}{l}\text { INDIRETA } \\
\text { multissetorialismo em } \\
\text { atividades paralelas (eventos, } \\
\text { fóruns e escolas de GI) }\end{array}$ & $\begin{array}{l}\text { INDIRETA } \\
\text { multissetorialismo em } \\
\text { atividades paralelas (mesa } \\
\text { colombiana de governança } \\
\text { da internet e eventos) }\end{array}$ & $\begin{array}{l}\text { INDIRETA } \\
\text { multissetorialismo em } \\
\text { atividades paralelas (eventos } \\
\text { e fóruns) }\end{array}$ \\
\hline
\end{tabular}

Fonte: elaboração própria a partir da legislação disponível e da coleta de dados dos autores. 
nados diretamente às entidades globais, como a ICANN. Afinal, conforme apontado por entrevistados, a diversidade de modelos de gestão permitiria aos ccTLDs "operar de forma eficiente e não engessada por políticas globais que não são pensadas para suas realidades locais" (entrevistado IV). Assim, o espaço dos ccTLDs seria "um reflexo da visão política dos países respectivos" (entrevistado XV). As comunidades associadas aos ccTLDs teriam a liberdade de propor soluções locais adaptadas para cada realidade, ora mais, ora menos submetidas à alçada estatal, embora procurem ampará-las interna e externamente no léxico multissetorial como fonte de legitimidade. Os conflitos emergentes entre interesses comerciais, empresariais e estatais poderiam ser metabolizados em um arranjo dinâmico e poroso à injunção de interesses privados. A depender do contexto e do momento político, o arranjo pode ser adaptado e isso seria feito por meio do apelo a uma regra de autoridade "multissetorial" como forma, mesmo que simbólica, de legitimação.

É importante salientar que o multissetorialismo parece funcionar como semântica legitimatória mesmo em contextos de claro domínio de um dos setores, muito embora tal apelo náo evite a continuidade de conflitos e disputas por poder e autoridade no respectivo regime. Nesse sentido, os regimes multissetoriais estão longe de representar um exemplo de experiência participativa e inclusiva, baseada na simetria entre diferentes setores e atores (Carr, 2015). Trata-se muito mais, e esse é o núcleo do nosso argumento, de uma regra de autoridade que possibilita a acomodação de diferentes arranjos de poder - mais, ou menos autoritários, e mais, ou menos participativos. $\mathrm{O}$ modelo multissetorial, como forma de legitimação do poder regulatório no contexto da GI, pode servir inclusive para reforçar a assimetria de poderes nos respectivos contextos em que é operacionalizado, podendo ser excludente e levar adiante a agenda de alguns dos setores envolvidos, em detrimento do restante da comunidade (Carr, 2015). Se o setor privilegiado será o estatal, o empresarial ou algum outro, dependerá das especificidades do contexto em que o regime evolui.

Contudo, mesmo que tenha significado apenas simbólico em alguns contextos, o multissetorialismo representa várias diferenças em relação aos conceitos clássicos de autoridade compreendida como resultante da legitimidade das normas jurídicas exclusivamente estatais (Troper, 2016). E, nesse sentido, seja como uma forma de acomodação de interesses ou como "regra de autoridade", ele consiste em um arranjo inovador digno de ser estudado e compreendido.

Para as teorias modernas do direito e da políti$\mathrm{ca}$, a autoridade depende da legitimidade, que passa a ser vista como sinônimo do conceito de legalidade (ou validade jurídica). Para o direito, a pergunta fundamental para a definição da autoridade consiste em determinar qual a regra que estabelece a validade das outras regras em um determinado sistema de regras. Usando a formulação de Herbert Hart, essa pergunta nos levaria a uma "regra de reconhecimento" que revelaria "os critérios através dos quais a validade das outras regras do sistema é avaliada" (1986, p. 117). Se a regra de reconhecimento fosse aquela que nos possibilitaria reconhecer a validade jurídica de determinada norma, a ela corresponderia, no plano político, uma regra de autoridade a estabelecer o critério que nos faça poder identificar quais atores têm autoridade para produzir normas consideradas obrigatórias.

O conceito de governança parece ser exatamente o melhor indicativo semântico de que o conceito moderno de autoridade sofreu profundas transformaçôes estruturais. Definida como um "governar sem governo", a noção de governança faz referência ao caráter heterárquico de regimes nos quais a autoridade para estabelecer normas não emana exclusivamente de um centro estatal e de seu respectivo ordenamento jurídico, mas deriva de sistemas de interação entre estruturas de mercado ou em redes complexas de atores que funcionam dotadas de múltiplas fontes de autoridade (Rhodes, 1996). Não se quer dizer, assim, que o Estado perde a soberania ou importância, mas que a noção de "autoridade pública, a coluna vertebral do Estado moderno, está sendo desafiada, modificada e complementada por outras formas de autoridade" (Flyverbom \& Bislev, 2008, p. 75), incluindo formas de autoridade privada e autoridade técnica (Porter, 2008; Porter \& Ronit, 2006).

Graças a mudanças estruturais da sociedade, extensivamente discutidas pela ciência política, o 
Estado sem dúvidas vê limitada sua capacidade de produzir regulaçáo de forma adequada e dinâmica o suficiente. E passa a delegar competências regulatórias para os próprios setores sociais a serem regulados, ou produzindo formas híbridas de regulação. Esse fenômeno passou a ser acompanhado pela literatura especializada, por meio de semânticas emergentes acerca autorregulação, meta-regulação e privatização que prosperaram a partir da década de 1990 (Rhodes, 2012; Stoker, 1998). Essa transformação implica igualmente uma mudança no significado de importantes distinçôes da teoria política moderna: a diferença estado/sociedade e de sua forma derivada público/privado (Horwitz, 1982).

Tanto no plano nacional, como no plano transnacional, identifica-se uma hibridização de formas jurídicas que torna problemática aquela diferença (Casini, 2014; Sand, 2013). De um lado, Estados introduzem formas de regulaçáo por meio de contratos, parcerias ou mesmo organizam seu funcionamento de acordo com regras típicas do direito privado (Casini, 2014; Rhodes, 1996). Por outro, Estados se submetem a regras produzidas por estruturas não-estatais, enquanto atores não-estatais produzem regulaçôes que incorporam a semântica do interesse público e princípios fundados na inclusão, na participaçấo, accountability e transparência (Casini, 2014). Essas formas de regulação, mesmo produzidas por atores privados, são vistas como legítimas pelos Estados e por outros atores privados, tendendo a interagir com o poder público, muitas vezes submetendo-o.

No caso dos domínios de código de país, tal processo é evidente: a tecnicidade exigida na gestáo dos recursos críticos, a novidade imposta pelo estabelecimento da internet como parte do cotidiano e a histórica proeminência dos atores privados no surgimento da internet geraram um ambiente fértil para a proliferação de arranjos que incluem os Estados, mas não são totalmente submetidos a eles. Um exemplo claro é a autoridade derivada do conhecimento especializado (Quack, 2016), algo que sempre foi evidente no caso da GI e que foi determinante para a emergência $\mathrm{da}$ autoridade de atores privados nesse contexto - um exercício de poder e autoridade que é muitas vezes assimétrico, mesmo quando recorre ao multissetorialismo como forma de legitimação.
Como já evidenciamos acima, acreditamos que a transformação da expressão da autoridade pode ser observada de forma modelar no caso da GI. Seja por conta de razôes estruturais, como por razóes históricas, a internet torna muito improvável o monopólio estatal puro e simples da regulação do setor. $\mathrm{O}$ desenvolvimento inicial, no meio universitário, fez da rede um ambiente ocupado por engenheiros, especialistas e hackers, em que inovaçôes e adaptaçôes precisavam ser constantemente discutidas e incorporadas, com pouco tempo para processos custosos de deliberação política (e estatal). Isso tornou tecnicamente necessária a inclusão de diferentes setores para tornar possível até mesmo a operação da rede. Por outro lado, os interesses de Estados e de grandes empresas também representam fontes legítimas e necessárias de impulso regulatório. Os Estados exercem autoridade, mas no caso dos ccTLDs estudados, com a exceção do caso argentino, o Estado foi um ator a integrar a comunidade posteriormente ou de forma tangencial, demandado por conflitos entre atores privados ou por uma concepção de defesa do interesse público. Mas, mesmo no caso argentino, o multissetorialismo surge como retórica legitimatória capaz de aproximar a GI da comunidade da internet local.

Tal centralidade simbólica do multissetorialismo para a gestáo dos ccTLDs parece mimetizar práticas históricas da governança global da internet. Um entrevistado do ". $m x$ " destacou como vantagem do multissetorialismo para um ccTLD a "abertura para se escutar imediatamente outros setores da sociedade, o que tem a ver com a forma como a gente trabalha na ICANN" (entrevistado X). A vivência do processo de deliberação e consenso presentes em espaços centrais da GI, como a ICANN, são identificados como um modelo para as esferas locais de gestão de recursos da internet. Repetindo: mesmo que essa percepçáo náo seja a realidade da GI, pode-se dizer que a retórica legitimatória conta como mecanismo importante para o exercício de autoridade. Nesse sentido, ao utilizarmos o adjetivo "simbólico", para nos referir ao caráter multissetorial da GI, queremos insistir que o simbolismo importa para o exercício da autoridade em qualquer nível da política. 
Na nossa compreensão, portanto, empresas, e também Estados, técnicos e especialistas apresentam pretensôes de produzir autoridade legítima para a regulação da internet. Mas o que torna a ICANN, o CGI.br, o NIC.ar, ou os outros órgãos regulatórios legítimos em seus respectivos contextos? Propomos aqui que o multissetorialismo funciona como uma retórica e uma estrutura para o estabelecimento de regulação legítima no interior da internet. Como colocado por Bislev e Flyverbom (2008, p. 82), "a confiança na participação multissetorial, tanto como discurso como tecnologia de governo" funciona não só como um "modo de governança subscrito pela maior parte dos diferentes participantes, mas também como um conjunto de princípios e objetivos para essa área emergente da governança transnacional”.

Mais recentemente, alguns Estados, como a China, lograram monopolizar em grande medida a GI nacional, com implicaçóes que hoje parecem ficar claras: um projeto de fragmentar a rede, com graves consequências para a conectividade mundial tal como a conhecemos (Kleinwächter, 2017). Apesar disso, no interior da internet, grande parte dos regimes nacionais de GI refletem o multissetorialismo como regra de autoridade para a gestáo dos seus recursos críticos.

\section{Conclusáo}

O desenvolvimento da GI se deu de forma relativamente independente do poder direto dos Estados nacionais. Mas, ao contrário do que pensavam seus fundadores, a internet não se revelou um espaço livre da interferência dos Estados e do poder político. Os ideais libertários que deram impulso criativo à rede tiveram que conviver com uma miríade de interesses estatais e econômicos a serem considerados no processo de regulaçáo da rede.

No caso da gestão dos domínios de topos de país, os ccTLDs, a trajetória de transformação da GI também pode ser verificada, mas com particularidades, dada a diferente origem de cada um dos modelos de governança. Nos casos estudados, vimos diferentes modelos originais. $\mathrm{E}$ vimos que todos eles convergiram, de forma mais ou menos explícita, e mais ou menos includente, para um modelo multissetorial em que diferentes setores $\mathrm{da}$ rede contribuem para a sua governança. Nesse sentido, o multissetorialismo parece funcionar como uma gramática capaz de oferecer uma regra de autoridade pós-estatal à GI. A produção de regulação no contexto dos recursos críticos da internet nacional apontaria assim para a emergência de novas formas de exercício de autoridade e poder.

Sem dúvida que, assim como o constitucionalismo estatal moderno, o multissetorialismo apresenta variaçóes. E muitas vezes ele oferece mais poder a um dos setores envolvidos. Nos casos estudados, ora o poder público, ora os interesses empresariais, ou ora o setor acadêmico universitário parecem ter papel mais relevante. Ademais, o multissetorialismo está longe de ser um arranjo constitucional includente e democrático. Aqueles que contam como stakeholders com poder de influir na GI são poucos. $\mathrm{E}$ as barreiras de entrada para a participação envolvem muitas vezes um tipo de conhecimento que pode operar de forma bastante excludente. Não faltam críticas à legitimidade e ao caráter excludente dos modelos multissetoriais (Carr, 2015). Cabe ao aprofundamento da pesquisa apontar as características inovadoras do multissetorialismo como forma de exercício de poder, evidenciando suas potencialidades, seus limites e seus problemas.

\section{Notas}

1 Essa nos parece ser a tradução mais adequada do termo inglês Multistakeholderism.

2 Country code top-level domain.

3 Em anexo, apresentamos os eventos que foram presenciados e a lista com os todos os atores entrevistados. Na técnica de snowball, uma entrevista com ator chave é usada para indicar quais os atores que deverão ser entrevistados em novas rodadas.

4 Internet Corporation for the Assignment of Number and Names.

5 Internet Assigned Numbers Authority.

6 National Telecommunications and Information Administration, Agência ligada ao Departamento de Comércio norte-americano para a regulação do setor.

7 Todas as traduçóes de originais foram feitas pelos autores. 
8 Ver o site do NIC.ar e do Internet Recorre, http:// ir.ar.

9 A licitação analisou o valor percentual da receita bruta a ser repassado trimestralmente ao MINTIC, que náo poderia ser menor do que $5,7 \%$ do faturamento, e deveria acompanhar em porcentagem o número de nomes de domínios registrados ao longo do tempo.

\section{BIBLIOGRAFIA}

ADACHI, Tomi. (2011), Comitê gestor da internet no Brasil (CGI.br): uma evolução do sistema de informação nacional moldada socialmente. Tese de Doutorado, Universidade de São Paulo, São Paulo.

AGUERRE, Carolina. (2015), La gobernanza de Internet: Argentina y Brasil en el contexto global.

TESE DE DOUTORADO, Universidade de Buenos Aires. Disponível em http://catalogosuba. sisbi.uba.ar/vufind/Record/http__www_sociales_uba_ar_tesis_ASO00000698, consultado em 08/12/2018.

AGUERRE, Carolina, \& GALPERIN, Hernan. (2015), Internet Policy Formation in Latin America: Understanding the links between the National, the Regional, and the Global (X GigaNet: Global Internet Governance Academic Network). Disponível em https://doi. org/10.2139/ssrn.2809883, consultado em 10/12/2018.

ALMEIDA, Virgílio; GETSCHKO, Demi., \& AFONSO, Carlos. (2015), "The Origin and Evolution of Multistakeholder Models". IEEE Internet Computing, 19(1): 99-126.

ANASTACIO, Kimberly. (2015), Participação na governança da Internet: o multissetorialismo do Comitê Gestor da Internet no Brasil (CGI.br). Dissertação de Mesrado, Universidade de Brasília, Brasília, DF.

ARGENTINA. RESOLUÇÃO 2.226, de 8 de agosto de 2000. Ministerio de Relaciones Exteriores, Comercio Internacional y Culto, Buenos Aires, ago 2000. Disponível em http:// servicios.infoleg.gob.ar/infolegInternet/anexos/60000-64999/64151/norma.htm, consultado em 12/12/2018.
ARGENTINA. Decreto Presidencial 2085, de 7 de dezembro de 2011. Administración Pública Nacional, Buenos Aires, dez 2011. Disponível em http://www.cac.com.ar/data/documentos/42_decreto\%202085.pdf, consultado em 12/12/2018.

ARGENTINA. Resolução 13, de 22 de abril de 2014. Ministerio de Planificacion Federal. Inversion Publica Y Servicios, Secretaria de Comunicaciones, Buenos Aires, abr 2014. Disponível em http:// www.informaticalegal.com.ar/2014/04/22/resolucion-no-132014-secretaria-de-comunicaciones-crea-la-comision-argentina-de-politicas-de-internet-capi/, consultado em 12/12/2018.

BARLOW, John Perry. (1996), "The Declaration of Independence of the Cyberspace". Disponível em https://www.eff.org/pt-br/cyberspace-independence consultado em 08/11/2018.

BISLEV, Sven \& FLYVERBOM, Mikkel. (2008), "Transnational private governance of the Internet: the roles of business", in J. C. Graz, \& A. Nölke (Eds.), Transnational Private Governance and its limits. London, New York, Routledge: 129-241.

BLACK, Julia. (2001), “Decentring Regulation: Understanding the Role Self-Regulation" in a 'Post- Regulatory' World”. Current Legal Problems, 54(1): 103-146.

BRASIL. Portaria Interministerial 147, de 31 de maio de 1995. Ministério das Comunicaçóes, Brasília, DF.

BRASIL. Decreto Presidencial 4.829, de 3 de setembro de 2003. Presidência da República, Casa Civil, Subchefia para Assuntos Jurídicos, Brasília, DF.

BRASIL. LEI 12.965, de 23 de abril de 2014. Presidência da República, Casa Civil, Subchefia para Assuntos Jurídicos, Brasília, DF.

CABASE. "Diez principios rectores de CABASE sobre Internet y la neutralidad de la red. 2012”. Disponível em http://www.cabase.org. ar/principios/, consultado em 21/11/2018.

CANABARRO, Diego Rafael. (2014), II Governança Global da Internet: tecnologia, poder e desenvolvimento. Tese de Doutorado. Universidade Federal do Rio Grande do Sul, Porto Alegre, RS. Disponível em ht- 
tps://www.lume.ufrgs.br/bitstream/handle/10183/114399/000953300-02 pdf?sequence $=2$, consultado em 28/10/2018.

CARR, Madeline. (2015), "Power plays in global internet governance". Millennium: Journal of International Studies, 43(2): 640-659.

CARVALHO, Menezes Revoredo. (2006), A trajetória da Internet no Brasil: do surgimento das redes de computadores à instituição dos mecanismos de governança. Dissertação de Mestrado, Universidade Federal do Rio de Janeiro, Rio de Janeiro, RJ.

CASINI, Lorenzo. (2014), "Down the rabbit-hole': The projection of the public/private distinction beyond the state". International Journal of Constitutional Law, 12(2): 402-428.

CHENOU, Jean-Marie. (2011), "Is Internet governance a democratic process ? Multistakeholderism and trasnational elites", (European Consortium for Political Research (ECPR) General Conference). Classic Elite Theory, Global Democratic Governance and the Emergence of Global Elites. Disponível em https://ecpr.eu/ filestore/paperproposal/1526f449-d7a7-4bed-b09a-31957971ef6b.pdf, consultado em $13 / 11 / 2018$.

CHENOU, Jean-Marie, \& RADU, Roxana. (2014), "Global Internet Policy: A Fifteen-Zear Long Debate”, in R. Radu, J. Chenou, \& R. H. Weber (Eds.), The Evolution of Global Internet Governance: Principles and Policies in the Making. Heidelberg, New York, London, Springer: 3-22.

COLÔMBIA. Lei 1065 de 2003. Congreso de Colombia. Disponível em http://www.latinoamericann.org/?q=node/1782, consultado em 12/12/2018.

COLÔMBIA. Resolução 284, de 21 de fevereiro de 2008. Ministerio de Tecnologías de la Información y las Comunicaciones. Bogotá. Disponível em http://www.informatica-juridica. $\mathrm{com} /$ resolucion/resolucion-284-modelo-operativo-la-administracion-del-dominio-co/, consultado em 14/10/2018.

COLÔMBIA. Resolução 1.250, de 23 de junho de 2008. Ministerio de Tecnologías de la Información y las Comunicaciones. Bogotá. Disponível em https:/www.alcaldiabogota.gov.co/
sisjur/normas/Norma1.jsp?i=32358, consultado em 14/10/2018.

COLÔMBIA. Resolução 1.652, de 3 de setembro de 2008. Ministerio de Tecnologías de la Información y las Comunicaciones. Bogotá. Disponível em https://www.alcaldiabogota.gov. $\mathrm{co} /$ sisjur/normas/Norma1.jsp?i=32350\&dt=S, consultado em 14/10/2018.

CUTLER, A. Claire. (2002), "Private international regimes and interfirm cooperation", in $\mathrm{R}$. B. Hall \& T. J. Biersteker (Eds.), The Emergence of Private Authority in Global Governance. Cambridge, Cambridge University Press, 23-42.

CUTLER, A. Claire. (2009), Private Power and Global Authority: Transnational Merchant Law in the Global Political Economy. (Cambridge Studies in International Relations). Cambridge, Cambridge University Press.

DAVIS, Kevin; FISCHER, Angela; KINSBURY, Benedict, \& MERRY, Sally Engle. (2012), Governance by indicators: Global Power through Quantification and Rankings. Oxford, Oxford University Press.

DENARDIS, Laura. (2014), The Global War for Internet Governance. New Haven, London, Yale University Press.

DORIA, Avri. (2013), "Use (and Abuse) of Multistekeholderism in the Internet", in R. Radu, J. Chenou, \& R. H. Weber (Eds.), The Evolution of Global Internet Governance: Principles and Policies in the Making. Heidelberg, New York, London, Springer: 115-138.

DREZNER, Daniel W. (2004), “The Global Governance of the Internet: Bringing the State Back". Political Science Quarterly, 119(3): 477-81.

DRORI, S. Gili, \& Meyer, J. W. (2006), "Scientization: Making the world safe for organizing", in M. L. Djelic \& K. Sahlin-Andersson (Eds.). Transnational Governance: Institutional Dynamics of Regulation. Cambridge, Cambridge University Press: 31-52.

ESPELAND, Wendy Nelson, \& SAUDER, Michael. (2007), "Rankings and Reactivity: How Public Measures Recreate Social Worlds". American Journal of Sociology, 113(1): 1-40.

FLYVERBOM, Mikkel, \& BISLEV, Sven. (2008), "Internet regulation-multi-stakeholder partici- 
pation and authority", in H. K. Hansen \& D. Salskov-Iversen (Eds.), Critical Perspectives on Private Authority in Global Politics. Basinstoke, Palgrave Macmillian: 72-90.

HALL, Rodney Bruce, \& BIERSTEKER, Thomas J. (2002a), The Emergence of Private Authority in Global Governance. Cambridge, Cambridge University Press.

HALL, Rodney Bruce, \& BIERSTEKER, Thomas J. (2002b), "The Emergence of Private Authority in the International System", in R. B. Hall $\&$ T. J. Biersteker (Eds.), The Emergence of Private Authority in Global Governance. Cambridge, Cambridge University Press: 3-22.

HANSEN, Hans Krause \& PORTER, Tony. (2017), "What do numbers do in global governance?”. Global Governance, 23(1): 31-42.

HART, Herbert L. A. (1986), O conceito de direito. Lisboa, Fundação Calouste Gulbenkien.

HIGGINS, Winton, \& HALLSTROM, Kristina Tamm. (2007), "Standardization, Globalization and Rationalities of Government". Organization, 14(5): 685-704.

HOFMANN, Jeanette; KATZENBACH, Christian, \& GOLLATZ, Kirsten. (2017), “Between coordination and regulation: Finding the governance in Internet governance", New Media and Society. 19(9): 1406-1423.

HORWITZ, Morton J. (1982), "The History of the Public/Private Distinction", University of Pennsylvania Law Review. 130(6): 1423-1428.

ITU/UN. (2005), Tunis Agenda for the Information Society, Pub. L. No. WSIS-05/TUNIS/ DOC/6(Rev. 1)-E. Disponível em https:// www.itu.int/net/wsis/docs2/tunis/off/6rev1. html, consultado em 12/12/2018.

KENNEDY, David. (2005). "Challenging Expert Rule: The Politics of Global Governance". Sydney Law Review, 27(01): 5-28.

KERSBERGEN, Kees Van, \& WAARDEN, Frans Van. (2004), “Governance”" as a bridge between disciplines: Cross-disciplinary inspiration regarding shifts in governance and problems of governability, accountability and legitimacy". European Journal of Political Research, 43(2): 143-171.

KJAER, Poul F. (2016), "From the Crisis of Corporatism to the Crisis of Governance", in P. F.
Kjaer \& N. Olsen (Eds.), Critical Theories of Crisis in Europe. Lanham, Rowman \& Littlefield, 125-140.

KLEINWÄCHTER, Wolfgang. (2007), “The History of Internet Governance. Governing the Internet”. Disponível em https://www.osce. org/fom/26169? download=true, consultado em 10/10/2018.

KLEINWÄCHTER, Wolfgang. (2017), “Nationalistic Hierarchies vs. Multistakeholder Networks?" Disponível em http://www.circleid. com/posts/20160106_internet_outlook_ 2017_nationalistic_hierarchies_multistakeholder/, consultado em 14/10/2018.

KRISCH, Niro. (2017), "Liquid authority in global governance". International Theory, 9(2): 237-260.

MACIEL, Marilia. (2014), “Creating a Global Internet Public Policy Space: Is There a Way Forward?” in W. J. Drake \& P. Monroe (Eds.), Beyond NetMundial: The Roadmap for Institutional Improvements to the Global Internet Governance Ecosystem. Annenberg School for Communication at the University of Pennsylvania. Disponível em https://global.asc.upenn. edu/app/uploads/2014/08/BeyondNETmundial_FINAL.pdf, consultado em 04/12/2018.

MÉXICO. Estrategia Digital Nacional, novembro de 2013. Gobierno de la República, Cidade do México. Disponível em http://cdn.mexicodigital.gob.mx/EstrategiaDigital.pdf, consultado em 14/10/2018.

MUELLER, Milton. (2017), Brazilian Internet Steering Committee under threat?. Internet Governance Project. Disponível em https:// www.internetgovernance.org/2017/08/17/ brazilian-internet-steering-committee-under-threat/, consultdo em 12/12/2018.

PORTER, Tony. (2008), "Disaggregating Authority in Global Governance", in H. K. Hansen \& D. Salskov-Iversen (Eds.), Critical Perspectives on Private Authority in Global Politics. London, New York, Routledge, 27-50.

PORTER, Tony, \& RONIT, Karsten. (2006), "Self-regulation as policy process: The multiple and criss-crossing stages of private rule-making”. Policy Sciences, 39(1): 41-72. 
QUACK, Sigrid. (2016), "Expertise and authority in transnational governance", in R. Cotterrell \& M. der Mar (Eds.), Authority in Transnational Legal Theory: Theorising Across Disciplines. Cheltenham, Northhampton, Edward Elgar: 361-386.

RADU, Roxana; CHENOU, Jean-Marie, \& WEBER, Rolf H. (2014), The Evolution of Global Internet Governance: Principles and Policies in the Making. Heidelberg, New York, London, Springer.

RAYMOND, Mark, \& DENARDIS, Laura. (2015), "Multistakeholderism: Anatomy of an inchoate global institution". International Theory, 7(3): 572-616.

RHODES, Rosamond Arthr William. (1996), "The New Governance: Governing without Government”. Political Studies, 44(4): 652667.

RHODES, Rosamond Arthr William. (2012), "Waves of Governance", in D. Levi-Faur (Ed.), The Oxford Handbook of Governance. Oxford, Oxford University Press: 33-48.

ROSENAU, James N. (2007), "Governing the ungovernable: The challenge of a global disaggregation of authority". Regulation \& Governance, 1(1): 88-97.

SAND, Inger-Johanne. (2013), "Globalization and the Transcendence of the Public/Private Divide: What is Public Law under Conditions of Globalization?” in C. M. Amhlaigh, C. Michelon, \& N. Walker (Eds.), After Public Law. Oxford, New York, Oxford University Press: 201-217.

SCHOLTE, Jean Aart. (2017), "Polycentrism and democracy in internet governance", in U. Kohl (Ed.), The Net and the Nation State: Multidisciplinary Perspectives on Internet Governance. Cambridge, Cambridge University Press: 165-184.

SCHOLTE, Jean Aart. (2004) "Globalization and governance: from statism to polycentrism". Change, (130): 185-223. Disponível em http://wrap.warwick.ac.uk/1984/, consultado em 04/12/2018.

STOKER, Gerry. (1998), "Governance as theory: five propositions”. International Social Science Journal, 50(155): 17-28.
SYLVAN, David. (2013), "Global Internet Governance: Governance without Governors", in R. Radu, J. Chenou, \& R. H. Weber (Eds.), The Evolution of Global Internet Governance: Principles and Policies in the Making. Heidelberg. New York, London, Springer: 23-36.

TROPER, Michel. (2016), "The modern state and the concept of authority", in $R$. Cotterrell \& M. Del Mar (Eds.), Authority in Transnational Legal Theory: Theorising Across Disciplines. Cheltenham, Northhampton, Edward Elgar: 75-95.

VAN EETEN, Michel G. J., \& Mueller, Mathiasson. (2013), "Where is the governance in Internet governance?" New Media and Society, 15(5): 720-736.

WEISER, Phil, \& WAZ, Joe. (2012), “Internet Governance: The Role of Multistakeholder Organizations". Journal of Telecommunications \& High Technology Law, 10(2): 331-350.

ZITTRAIN, Jonathann. (1999), "ICANN: Between the Public and and the Private Comments Before Congress". Berkeley Technology Law Journal, 14(3): 1071-1093.

ZUMBANSEN, Peer. (2012), "Governance: An Interdisciplinary Perspective”, in D. Levi-Faur (Ed.), Oxford Handbook of Governance. Oxford, Oxford University Press: 83-96. 


\section{ANEXO - LISTA DE EVENTOS E ENTREVISTAS}

\section{REUNIÓES E FÓRUNS}

\section{Internet Governance Forum (IGF)}

Participaçóes em 2015 (João Pessoa), 2016 (Cidade do México) e 2017 (Genebra)

O IGF congrega, uma vez ao ano, distintos stakeholders em reunióes construídas a partir de oficinas e palestras propostas pelos próprios participantes, sendo obrigatória a composiçấo multissetorial de painelistas e proponentes. O evento é atrelado às Naçōes Unidas e é fruto da Cúpula Mundial sobre a Sociedade da Informação (CMSI). Desde a sua criação, em 2006, o fórum tem sido amplamente estudado, sobretudo a partir da identificação do seu impacto sobre as decisōes da GI.

A participação em três ediçóes do evento permitiu uma observação dos acordos e desacordos entre stakeholders antes, durante e após cada IGF. Participamos na articulação prévia entre atores propondo painéis, estivemos presencialmente nos debates em cada um dos fóruns e, posteriormente, acompanhamos o processo de escolha dos comitês responsáveis pela administração do evento.

\section{Fórum da Internet no Brasil (FIB)}

Participaçôes em 2015 (Salvador), 2016 (Porto Alegre) e 2017 (Rio de Janeiro)

O FIB é a versão brasileira do IGF, realizada uma vez por ano em preparação ao evento global. O Fórum também é estruturado a partir de painéis sugeridos pela comunidade, com obrigação de composição multissetorial.

A participação em três ediçóes do evento per- mitiu a vivência da tentativa brasileira de assegurar, em solo nacional, prática comum da governança da internet global de promoção de espaços de discussão multissetorial.

\section{Taller de Políticas y Legal da Organizaçáo Latino-americana e do Caribe de ccTLDs (LACTLD)}

\section{Participação em 2017 (Foz do Iguaçu)}

Reunião da associação que congrega os ccTLDs da região, inclusive os quatro analisados pelo artigo, que ocorreu durante o $27^{\circ}$ Encontro do Registro de Endereços da Internet para a América Latina e o Caribe (LACNIC).

A participação nas partes públicas da reunião (houve momentos exclusivos para os membros ativos da organizaçáo) viabilizou o acompanhamento de debates entre ccTLDs sobre políticas para a região. $\mathrm{O}$ embate de visóes entre os representantes dos ccTLDs e demais participantes foi observado. Por exemplo, durante a reunião, um representante da ICANN utilizou sem querer a palavra "contrato" para se referir à relaçáo dos ccTLDs com a Corporação. Tal fala gerou tensão entre os presentes, na medida em que os ccTLDs não têm necessariamente contratos formais com a entidade e podem se incomodar com a possibilidade de alguma submissão. A fala foi logo rebatida, gentilmente, por alguns dos presentes. 


\section{LISTA DE ENTREVISTADOS}

Os autores buscaram contato com os dirigentes de cada ccTLD e, a partir da indicação deles, fizeram outras entrevistas (snowball).

\begin{tabular}{|c|c|c|}
\hline ORGANIZAÇÁO & DATA & COMENTÁRIOS \\
\hline \multicolumn{3}{|c|}{ DIRETAMENTE ENVOLVIDOS COM OS CCTLDS ANALISADOS } \\
\hline (I) NIC.ar & $\begin{array}{l}\text { maio/2017 } \\
\text { julho/2017 }\end{array}$ & $\begin{array}{l}\text { I - Presencial (reunião do LACTLD) } \\
- \\
\text { II - Remota }\end{array}$ \\
\hline (II) NIC.ar & $\begin{array}{l}\text { maio/2017 } \\
\text { julho/2017 }\end{array}$ & $\begin{array}{l}\text { I - Presencial (reunião do LACTLD) } \\
- \\
\text { II - Remota }\end{array}$ \\
\hline (III) .CO SAS & $\begin{array}{l}\text { maio/2017 } \\
\text { julho/2017 }\end{array}$ & $\begin{array}{l}\text { I - Presencial (reunião do LACTLD) } \\
- \\
\text { II - Remota }\end{array}$ \\
\hline (IV) CGI.BR & $\begin{array}{l}\text { abril/2017 } \\
\text { agosto/2017 }\end{array}$ & $\begin{array}{l}\text { I - Presencial (visita à sede do CGI.br) } \\
- \\
\text { II - Remota }\end{array}$ \\
\hline (V) NIC.BR & abril/2017 & Presencial (visita à sede do CGI.br) \\
\hline (VI) NIC.mx & outubro/2017 & Remota \\
\hline $\begin{array}{l}\text { (VII) LACNIC e ex-funcionário do } \\
\text { NIC.mx) }\end{array}$ & julho/2017 & Remota \\
\hline (VIII) MINTIC (.co) & setembro/2017 & Remota \\
\hline $\begin{array}{l}\text { (IX) Ex-funcionário da Organizaçáo } \\
\text { Latinoamericana e do Caribe de } \\
\text { ccTLDs (LACTLD) }\end{array}$ & julho/2017 & Remota \\
\hline (X) Funcionário da ICANN LATAM & agosto/2017 & Remota \\
\hline $\begin{array}{l}\text { (XI) Membro do Country Code Names } \\
\text { Suporting Organization (ccNSO, parte da } \\
\text { ICANN envolvida com os ccTLDs) }\end{array}$ & fevereiro/2018 & Remota \\
\hline $\begin{array}{l}\text { (XII) Membro da Non-Comercial Isers } \\
\text { Constituency (NCUC), parte da ICANN } \\
\text { atrelada à sociedade civil }\end{array}$ & outubro/2017 & Remota \\
\hline $\begin{array}{l}\text { (XIII) Representante do .ar no } \\
\text { Governmental Advisory Committee } \\
\text { (GAC) }\end{array}$ & julho/2017 & Remota \\
\hline
\end{tabular}




\begin{tabular}{|c|c|c|}
\hline ORGANIZAÇÃO & DATA & COMENTÁRIOS \\
\hline \multicolumn{3}{|c|}{ INDIRETAMENTE ENVOLVIDOS COM OS CCTLDS ANALISADOS } \\
\hline $\begin{array}{l}\text { (XIV) Representante do .rs (Sérvia) } \\
\text { no ccNSO }\end{array}$ & agosto/2017 & Remota \\
\hline $\begin{array}{l}\text { (XV) Representante do .uk (Reino } \\
\text { Unido no GAC }\end{array}$ & julho/2017 & Remota \\
\hline (XVI) Representante do .uk no ccNSO & agosto/2017 & Remota \\
\hline $\begin{array}{l}\text { (XVII) Com Laude (grande revendedora } \\
\text { de domínios) }\end{array}$ & agosto/2017 & Remota \\
\hline
\end{tabular}




\section{AUTORIDADE PRIVADA NA GOVERNANÇA DA INTERNET: REGIMES DE NOMES E DOMÍNIOS NA AMÉRICA LATINA}

\section{Pablo Holmes e Kimberly Anastácio}

Palavras-chave: Governança; Autoridade privada; Governança da internet; ccTLDs

$\mathrm{O}$ artigo dialoga com a literatura da ciência política e das relaçóes internacionais sobre governança e sobre a emergência de formas de autoridade náo-estatais, para observar a emergência de autoridade privada na regulaçáo dos recursos críticos da internet a partir da afirmação do modelo multissetorial. Para tanto, baseia-se em pesquisa comparativa entre os modelos de governança dos domínios nacionais de nível superior (ccTLDs) de quatro países latino-americanos: Argentina, Brasil, México e Colômbia. Com pesquisa documental e entrevistas feitas com os setores governamentais e náo-governamentais, demonstra-se que, apesar de trajetórias bastante diversas, esses regimes convergem, ao menos nominalmente, para um arranjo multissetorial. Mesmo com limites, o multissetorialismo serve como regra de autoridade, náo podendo ser compreendido a partir de teorias clássicas de regulação fundadas em modelos hierárquicos e centradas no Estado.

\section{PRIVATE AUTHORITY IN INTERNET GOVERNANCE: NAME AND DOMAIN REGIMES IN THE LATIN AMERICAN CONTEXT}

\section{Pablo Holmes and Kimberly Anastácio}

Keywords: Governance; Private Authority; Internet Governance in Latin America; ccTLDs

This paper offers comparative research on four different models of multistakeholder governance for the critical resources of the Internet (v. g. national top-level domains or ccTLDs) in Brazil, Colombia, Argentina, and Mexico, while engaging with the ongoing debate over Internet governance and its relations with emerging forms of private authority. Based on an extensive range of interviews with governmental and non-governmental actors, it argues that multistakeholderism may function as a specific rule of authority for the national regimes of Internet Governance. This hypothesis suggests a profound transformation in the modern structures of governing since heterarchy replaces hierarchy in the building of regulatory arrangements.

\section{L'AUTORITÉ PRIVÉE DANS LA GOUVERNANCE DE L'INTERNET: RÉGIMES DE NOMS ET DOMAINES EN AMÉRIQUE LATINE}

\author{
Pablo Holmes et Kimberly Anastácio \\ Mots-clés: Gouvernance; Autorité pri- \\ vée; Gouvernance de l'Internet; ccTLDs
}

L'article dialogue avec la littérature des sciences politiques et les relations internationales à propos de la gouvernance et de l'émergence de formes d'autorité non étatique, afin d'observer l'émergence de l'autorité privée dans la régulation des ressources critiques de l'Internet à partir de l'affirmation du modèle multisectoriel. Il s'appuie, pour cela, sur des recherches comparatives entre les modèles de gouvernance des domaines nationaux de niveau supérieur (ccTLDs) de quatre pays d'Amérique latine : l'Argentine, le Brésil, le Mexique et la Colombie. Grâce à la recherche documentaire et aux entretiens réalisés avec les secteurs gouvernementaux et non gouvernementaux, nous démontrons que, malgré des trajectoires très diverses, ces régimes convergent, du moins nominalement, vers un arrangement multisectoriel. Même avec des limites, le multisectorialisme sert de règle d'autorité et ne peut être compris à partir des théories réglementaires classiques fondées sur des modèles hiérarchiques et centrés sur l'État. 